\title{
Exogenous expression of miRNA-3613-3p causes APAF1 downregulation and affects several proteins involved in apoptosis in BE(2)-C human neuroblastoma cells
}

\author{
IWONA NOWAK, ELŻBIETA BORATYN, MAŁGORZATA DURBAS, IRENA HORWACIK and HANNA ROKITA
}

\author{
Laboratory of Molecular Genetics and Virology, Faculty of Biochemistry, \\ Biophysics and Biotechnology, Jagiellonian University, 30-387 Kraków, Poland
}

Received March 1, 2018; Accepted July 2, 2018

DOI: 10.3892/ijo.2018.4509

\begin{abstract}
MicroRNAs (miRNAs) are a class of small non-coding RNAs involved in post-transcriptional gene regulation. Furthermore, dysregulation of miRNA expression is an important factor in the pathogenesis of neuroblastoma. Our previous study identified that overexpression of monocyte chemoattractant protein-induced protein 1 protein led to a significant downregulation of a novel miRNA molecule, miRNA-3613-3p. In the present study, the potential involvement of miRNA-3613-3p in the cell biology of neuroblastoma was investigated. It was identified that the expression of miRNA-3613-3p varies among a range of human neuroblastoma cell lines. As the delineation of the functions of a miRNA requires the identification of its target genes, seven putative mRNAs that may be regulated by miRNA-3613-3p were selected. Furthermore, it was identified that overexpression of miRNA-3613-3p causes significant downregulation of several genes exhibiting tumor suppressive potential [encoding apoptotic protease-activating factor 1 (APAF1), Dicer, DNA fragmentation factor subunit $\beta$, von Hippel-Lindau protein and neurofibromin 1] in BE(2)-C human neuroblastoma cells. APAF1 mRNA was the most significantly decreased transcript in the cells with miRNA-3613-3p overexpression. In accordance with the aforementioned results, the downregulation of cleaved caspase- 9 and lack of activation of executive caspases in BE(2)-C cells following miRNA-3613-3p overexpression was observed. The results of the present study suggest a potential underlying molecular mechanism of apoptosis inhibition via $A P A F 1$ downregulation in human neuroblastoma $\mathrm{BE}(2)-\mathrm{C}$ cells with miRNA-3613-3p overexpression.
\end{abstract}

Correspondence to: Ms. Iwona Nowak, Laboratory of Molecular Genetics and Virology, Faculty of Biochemistry, Biophysics and Biotechnology, Jagiellonian University, Gronostajowa st. 7, 30-387 Kraków, Poland

E-mail: iwonka.nowak@uj.edu.pl

Key words: microRNA, microRNA-3613-3p, neuroblastoma, apoptotic protease-activating factor 1 , apoptosis

\section{Introduction}

Neuroblastoma is the most common type of extracranial solid tumor in children. It arises from cells of sympathoadrenal lineage from the neural crest, which migrate away from their place of origin during embryogenesis. Primary tumors typically occur in the adrenal glands, chest, head, neck and pelvis (1). The clinical presentation of neuroblastoma varies from spontaneous regression to rapid progression despite multimodal therapies. This depends on the age of the patient at diagnosis, as well as genetic prognostic factors, with the most important being N-Myc $(M Y C N)$ gene amplification, which occurs in $25 \%$ of tumors (2). Annually, $>600$ novel cases of neuroblastoma are recognized in the USA, with $\sim 50 \%$ of the patients being diagnosed at the advanced stages of the disease (1). The outcome of therapy of high-risk neuroblastoma cases remains poor, with the long-term survival rate being $<50 \%$ (3).

Recently, assessments of serum microRNAs (miRNAs) have developed into promising non-invasive diagnostic tools for patients, including those with neuroblastoma (4). miRNAs are small non-coding RNA molecules that function as negative regulators of gene expression at the post-transcriptional level. The expression of $>60 \%$ of protein-coding genes is considered to be regulated by miRNAs. One transcript can be recognized by numerous miRNAs, whereas one miRNA is able to regulate a number of mRNAs. Therefore, the expression of miRNAs must be tightly regulated to ensure normal growth and development of an organism (5). Dysregulation of miRNA expression contributes to tumor progression in numerous types of cancer, including neuroblastoma (5). Certain miRNA molecules, such as miRNA-34a and miRNA-17-92, have been described as potent tumor suppressors and oncogenes in neuroblastoma, respectively (6). This is due to their involvement in the regulation of the tumor phenotype via control of cellular processes, including proliferation, differentiation and apoptosis (6). Although the function of several individual miRNA molecules has been elucidated in neuroblastoma (5), the functions of numerous miRNAs require experimental delineation.

miRNA-3613-3p is a novel miRNA molecule, which attracted interest in our previous study during screening for differentially expressed miRNAs in $\mathrm{BE}(2)-\mathrm{C}$ neuroblastoma 
cells with monocyte chemoattractant protein-induced protein 1 (MCPIPl) overexpression (7). It was identified that the overexpression of MCPIP1 causes significant downregulation of miRNA-3613-3p expression in BE(2)-C cells as well as the upregulation of several putative target genes of miRNA-3613-3p (7). To date, the expression of miRNA-3613-3p has been demonstrated by several other groups (8-13). However, the effect of miRNA-3613-3p overexpression on cell viability has only been studied in one type of cell. Zhang et al (14) identified that miRNA-3613-3p led to a significant downregulation of cell proliferation via negative regulation of genes encoding cyclin-dependent kinase 1, NUF2 NDC80 kinetochore complex component, baculoviral inhibitor of apoptosis protein repeat-containing 5 , ZW10-interacting kinetochore protein and SPC24 NDC80 kinetochore complex component in human HepG2 hepatoblastoma cells. Furthermore, miRNA-3613-3p was identified among five miRNA molecules as a central regulatory factor in RNA interference-dependent control of p53 expression in the aforementioned cell line (15). Additionally, the expression of miRNA-3613-3p was low in the hepatocytes and serum of patients with acute viral hepatitis caused by hepatitis B virus and was associated with possible downregulation of signal transducer and activator of transcription 3 expression due to specific binding with miRNA-3613-3p (13). Another premise of involvement of miRNA-3616-3p in cancer is its potential biomarker value in adenocarcinoma (11) and the enrichment of the complementary strand of the mature miRNA-3613-3p in exosomes derived from a colon cancer cell line (9). Deregulated expression of miRNA-3613-3p has also been identified in several other pathological states $(8,10,12)$. Nevertheless, the involvement of miRNA-3613-3p in the pathogenesis of neuroblastoma remains to be elucidated.

On the basis of our previous study (7), it was decided to investigate the potential functions of miRNA-3613-3p in neuroblastoma. First, the differential expression of miRNA-3613-3p was assessed in a range of human neuroblastoma cell lines. Furthermore, the seven putative target genes of miRNA-3613-3p were investigated using extensive bioinformatics analysis. In order to verify the interaction between miRNA-3613-3p and its predicted target mRNAs, three steps were performed. The expression of the seven proposed target genes was investigated in BE(2)-C human neuroblastoma cells transfected with miRNA-3613-3p mimic using the reverse transcription-quantitative polymerase chain reaction (RT-qPCR). The expression of the selected putative target genes was analyzed at the protein level using western blotting. The predicted binding sites in the apoptotic protease-activating factor $1(A P A F 1) 3$ ' untranslated region (3'UTR) were verified using a luciferase reporter assay. Additionally, the effect of enforced miRNA-3613-3p expression on $\mathrm{BE}(2)-\mathrm{C}$ human neuroblastoma cell viability. was assessed. Furthermore, the expression and activation levels of several proteins involved in apoptosis in $\mathrm{BE}(2)-\mathrm{C}$ cells overexpressing miRNA-3613-3p were investigated.

\section{Materials and methods}

Cell culture. Seven human neuroblastoma cell lines, BE(2)-C [American Type Culture Collection (ATCC), Manassas, VA, USA], Kelly [Deutsche Sammlung von Mikroorganismen und
Zellkulturen GmbH (DSMZ), Leibniz, Germany], IMR-32 (ATCC), SK-N-SH (ATCC), CHP-134 [European Collection of Authenticated Cell Cultures (ECACC), Porton Down, UK], LAN-1 (DSMZ) and LAN-5 (DSMZ), and a prostate cancer cell line PC3 (ECACC) were cultured at $37^{\circ} \mathrm{C}$ in an incubator with $5 \% \mathrm{CO}_{2}$. Cells were routinely screened for Mycoplasma contamination and all tests were negative according to a MycoAlert $^{\mathrm{TM}}$ Mycoplasma Detection kit (Lonza Group, Ltd., Basel, Switzerland). LAN-1 cells were cultured in a 1:1 mixture of Eagle's minimal essential medium and Ham's F12 medium (both from Sigma-Aldrich; Merck KGaA, Darmstadt, Germany) supplemented with $10 \%$ fetal bovine serum (Gibco; Thermo Fisher Scientific, Inc., Waltham, MA, USA). BE(2)-C cells were cultured in a 1:1 mixture of Eagle's minimal essential medium and Ham's F12 medium supplemented with non-essential amino acids (NEAA), $1 \mathrm{mM}$ sodium pyruvate and $10 \%$ fetal bovine serum. Kelly and CHP-134 cells were cultured in RPMI-1640 (Sigma-Aldrich; Merck KGaA) with 10\% fetal bovine serum. IMR-32 and SK-N-SH cells were cultured in Eagle's minimal essential medium supplemented with $10 \%$ fetal bovine serum, $1 \%$ NEAA solution and $1 \mathrm{mM}$ sodium pyruvate. LAN-5 cells were cultured in RPMI-1640 supplemented with $20 \%$ fetal bovine serum. The PC3 cell line was cultured in a 1:1 mixture of Ham's F12 medium and Dulbecco's modified Eagle's medium (Sigma-Aldrich; Merck KGaA) with 10\% fetal bovine serum. All neuroblastoma cell culture media were additionally supplemented with $50 \mu \mathrm{g} / \mathrm{ml}$ gentamicin (Sigma-Aldrich; Merck KGaA), whereas the PC 3 cell culture was supplemented with $40 \mu \mathrm{g} / \mathrm{ml}$ gentamicin.

Generation of the genetic construct. A fragment of APAFI (NCBI accession no. NM_013229.2) 3'UTR containing putative binding sites for miRNA-3613-3p was amplified from $\mathrm{BE}(2)-\mathrm{C}$ cells by PCR using primers with recognition sites for XhoI and SalI restriction enzymes added at the $5^{\prime}$ end (forward, 5'-ACCTGCTCGAGAAATTGGTATTTTAATACTG-3' and reverse, 5'-AGTAAGTCGACAGCAAGACTCTGTCTC CAA-3'). For the amplification of the 3'UTR fragment DyNAzyme II DNA Polymerase (Thermo Fisher Scientific, Inc.) was used following the manufacturer's protocol. The thermocycling conditions were: Pre-incubation at $94^{\circ} \mathrm{C}$ for $3 \mathrm{~min} ; 35$ cycles of denaturation at $94^{\circ} \mathrm{C}$ for $30 \mathrm{sec}$, annealing at $55^{\circ} \mathrm{C}$ for $30 \mathrm{sec}$ and elongation at $72^{\circ} \mathrm{C}$ for $30 \mathrm{sec}$; final elongation at $72^{\circ} \mathrm{C}$ for $10 \mathrm{~min}$. Next, the products were separated by agarose gel electrophoresis using a $1 \%$ gel, visualized using SimplySafe ${ }^{\mathrm{TM}}$ (Eurx, Gdańsk, Poland) and isolated using the Gel-Out kit (A\&A Biotechnology, Gdynia, Poland) according to the manufacturer's protocol. Isolated products and pmiRGlo plasmid vector (E1330; Promega Corporation, Madison, WI, USA) were digested using XhoI and SalI restriction enzymes. Following digestion, the pmiRGlo plasmid was additionally dephosphorylated using calf intestinal alkaline phosphatase. Next, DNA was purified using a QIAquick Nucleotide Removal kit (Qiagen GmbH, Hilden, Germany). The APAF1 3'UTR fragment was incorporated into the pmiRGlo plasmid vector using T4 DNA ligase. The genetic construct obtained was verified using DNA sequencing (Genomed, Warszawa, Poland).

Cell transfection with miRNA-3613-3p mimic. miRNA-3613-3p mimic (cat. no. 4464066) and scrambled oligonucleotide (cat. 
no. 4464058), lacking complementarity to sequences in the human transcriptome, as a negative control were purchased from Ambion; Thermo Fisher Scientific, Inc. For enforced overexpression of miRNA-3613-3p, BE(2)-C cells were seeded at a density of $3 \times 10^{4}$ cells $/ \mathrm{cm}^{2}$ in complete medium as aforementioned. After $24 \mathrm{~h}$ of culture, the medium was changed. miRNA mimic or negative control and Lipofectamine ${ }^{\circledR} 2000$ (Thermo Fisher Scientific, Inc.) were diluted in Opti-MEM ${ }^{\mathrm{TM}}$ (Gibco; Thermo Fisher Scientific, Inc.), and added to the cell culture at final concentrations of 30,40 and $50 \mathrm{nM}$. Transfected cells were passaged after $24 \mathrm{~h}$. For prolonged overexpression of miRNA-3613-3p, miRNA-3613-3p mimic or negative control and Lipofectamine 2000 diluted in Opti-MEM were added to the transfected cells culture after $48 \mathrm{~h}$. Overexpression of miRNA-3613-3p was verified using RT-qPCR.

LAN-1 cell transfection with miRNA-3613-3p inhibitors. miRNA-3613-3p inhibitor (cat. no. 4464084) and corresponding negative control (cat. no. 4464076) were purchased from Ambion; Thermo Fisher Scientific, Inc. For the silencing of miRNA-3613-3p, LAN-1 neuroblastoma cells were seeded at a density of $2.6 \times 10^{4}$ cells $/ \mathrm{cm}^{2}$ in complete medium as aforementioned. After $24 \mathrm{~h}$ of culture, the medium was changed. The miRNA-3613-3p inhibitor, negative control and Lipofectamine 2000 transfection agent were diluted in Opti-MEM. The inhibitor and negative control were added to the cell culture at a final concentration of $30 \mathrm{nM}$. Cells were collected $48 \mathrm{~h}$ after transfection.

Kelly cell transfection with genetic constructs containing an expression cassette for wild-type or mutated MCPIPI protein. Plasmid vectors used to obtain enforced expression of MCPIP1 protein were as described previously (16). The transfection procedure for Kelly cells was as described in our previous study (17). Overexpression of wild-type or mutated MCPIP1 protein was verified by western blotting.

RNA isolation. RNA was extracted from cells using TRI-REAGENT ${ }^{\circledR}$ (Lab Empire, Rzeszów, Poland) according to the manufacturer's protocol. The concentration and purity of the isolated RNA were determined using a NanoDrop ND-1000 spectrophotometer (Thermo Fisher Scientific, Inc.). The integrity of the RNA was verified by agarose gel electrophoresis using a $1 \%$ gel.

$m R N A R T-q P C R$. For each sample, $500 \mathrm{ng}$ of RNA was reverse-transcribed using Moloney murine leukemia virus reverse transcriptase (Thermo Fisher Scientific, Inc.), according to the manufacturer's protocol, using a GenAmp thermocycler (PerkinElmer, Inc., Waltham, MA, USA). qPCR was performed using an Eco thermocycler (Illumina, San Diego, CA, USA) with KAPA SYBR ${ }^{\circledR}$ FAST qPCR Master mix (Kapa Biosystems, Inc., Wilmington, MA, USA). The thermocycling conditions were: Pre-incubation at $95^{\circ} \mathrm{C}$ for $10 \mathrm{~min}$; 40 cycles of denaturation at $95^{\circ} \mathrm{C}$ for $15 \mathrm{sec}$, and annealing and elongation at $60^{\circ} \mathrm{C}$ for $30 \mathrm{sec}$; a melting cycle at $95^{\circ} \mathrm{C}$ for $15 \mathrm{sec}, 55^{\circ} \mathrm{C}$ for $15 \mathrm{sec}$ and $95^{\circ} \mathrm{C}$ for $15 \mathrm{sec}$. The cDNA used for qPCR was diluted 50 -fold, and the reference gene 40S ribosomal protein $\mathrm{S} 13$ (RPS13) was used. The primers for DICER, APAF1, DNA fragmentation factor subunit $\beta(D F F B)$, neurofibromin $1(N F 1)$, retinoic acid-related orphan receptor $\alpha(R O R A)$, kinesin family member 3A (KIF3A) and RPS13 used in these experiments were described previously (7). The sequences of von Hippel-Lindau protein $(V H L)$ primers were as follows: Forward, 5'-TCCACAGCTACCGAGGTCA-3' and reverse, 5'-GGCAAA AATAGGCTGTCCGT-3'. All experiments were performed in triplicate at least three times. For quantification of the relative mRNA level, the $\Delta \Delta \mathrm{Cq}$ method was used (18).

miRNA RT-qPCR. RT of miRNAs was performed using miRCURY LNA ${ }^{\mathrm{TM}}$ Universal RT microRNA PCR (Exiqon; Qiagen $\mathrm{GmbH}$ ). For each reaction, $100 \mathrm{ng}$ total RNA was used. miRNA RT-qPCR experiments were performed using miRCURY LNA microRNA PCR and ExiLENT SYBR Green master mix (Exiqon; Qiagen $\mathrm{GmbH}$ ), according to the manufacturer's protocol. For the PCR, the cDNA was diluted 80 -fold and U6 small nuclear RNA (snRNA) was used as the reference. Primers for miRNA-3613-3p (cat. no. 2100646) and the reference U6 snRNA (cat. no. 203907) were provided by Exiqon; Qiagen GmbH. All RT-qPCR experiments were performed in triplicate at least three times, and the $\Delta \Delta \mathrm{Cq}$ method (18) was used to quantify the relative level of miRNA-3613-3p.

Protein extraction and western blot analysis. Protein extraction was performed using TRI-REAGENT, according to the manufacturer's protocol. Protein concentration was assessed using the bicinchoninic acid method (19). Protein extracts were resolved using SDS-PAGE (8, 12 or $15 \%$ gel, depending on the protein weight). Subsequently, the western blotting procedure was performed as described previously (20). The following primary antibodies purchased from Cell Signaling Technology, Inc. (Danvers, MA, USA) were used: Anti-DICER rabbit monoclonal antibody (mAb) (cat. no. 5362, 1:1,000); anti-APAF1 rabbit mAb (cat. no. 8723, 1:1,000); anti-caspase-9 mouse mAb (cat. no. 9508, 1:1,000); anti-cleaved caspase-9 rabbit mAb (cat. no. 7237, 1:10,00); anti-caspase-7 rabbit mAb (cat. no. 12827, 1:1,000); anti-cleaved caspase-7 rabbit mAb (cat. no. 8438, 1:1,000); anti-poly(ADP-ribose) polymerase (PARP) rabbit $\mathrm{mAb}$ (cat. no. 9542, 1:1,000); anti-caspase-3 rabbit mAb (cat. no. 9665, 1:1,000); anti-cleaved caspase-3 rabbit mAb (cat. no. 9664, 1:1,000); and anti- $\alpha$-tubulin rabbit mAb (cat. no. 2144, 1:1,000). Anti-rabbit IgG goat mAb (cat. no. 7074, 1:2,000; Cell Signaling Technology, Inc.) and anti-mouse IgG rabbit polyclonal antibody (cat. no. A-9044, 1:40,000; Sigma-Aldrich; Merck KGaA) conjugated to horseradish peroxidase were used as the secondary antibodies. The relative protein levels were determined using densitometric scanning of immunoreactive bands using Quantity One software (version 4.6.9; Bio-Rad Laboratories, Inc., Hercules, CA, USA) and normalized to $\alpha$-tubulin levels.

Cell viability assay. BE(2)-C cells were cultured in 96-well plates and transfected with miRNA-3613-3p mimic or negative control. After $48 \mathrm{~h}$, the transfection with miRNA-3613-3p mimic or negative control was repeated as aforementioned. Cellular ATP levels were assessed using an ATPlite Luminescence ATP Detection assay system (PerkinElmer, Inc.), according to the manufacturer's protocol. Luminescence signals were determined using an Infinite M200 luminescence reader (Tecan Group, Ltd., Mannedorf, Switzerland). The experiment was performed three times. 
Luciferase reporter assay. $\mathrm{BE}(2)-\mathrm{C}$ cells were seeded in the 96-well plates and cultured in complete medium for $24 \mathrm{~h}$. Next, the cells were co-transfected with $40 \mathrm{nM}$ miRNA-3613-3p mimic or negative control, and $300 \mathrm{ng}$ pmiRGlo plasmid vector with the cloned fragment of APAF1 3'UTR or empty pmiRGlo plasmid vector. Luciferase activity was assessed using the Dual-Luciferase Reporter assay system (Promega Corporation), according to the manufacturer's protocol $48 \mathrm{~h}$ after co-transfection. Determination of luminescence signals from firefly and Renilla luciferases was performed using an Infinite M200 luminescence reader. The experiment was performed three times.

Bioinformatics analysis. Visualization of the precursor form of the miRNA-3613-3p was generated using the Mfold algorithm (unafold.rna.albany.edu/?q=mfold/download-mfold). Additionally, miRNA-3613-3p was subjected to analysis using the miRPath version 3.0 web server algorithm (21). Biological processes potentially regulated by the miRNA were examined using microT-CDS (22). For the Kyoto Encyclopedia or Genes and Genomes (www.genome.jp/kegg) pathway enrichment analysis, $\mathrm{P}<0.05$ was considered to indicate a statistically significant difference and the threshold for microT-CDS was 0.8 . Furthermore, the predicted target genes of miRNA-3613-3p were determined using the miRWalk2.0 database (23), and the enriched functional patterns from the PANTHER (www.pantherdb.org/about.jsp) and Gene Ontology algorithms (geneontology.org) were analyzed. Furthermore, the visualization of miRNA-mRNA duplexes and calculation of free energies of each binding was performed using the RNAhybrid tool (24). In addition, the difference in the free energy of each base-pairing interaction between miRNA and mRNA was determined using the PITA algorithm (25). In order to determine the cross-species conservation of putative binding sites of miRNA-3613-3p, the TargetScan algorithm was used (26).

Statistical analysis. Data are presented as the mean \pm standard error of the mean. All experiments were performed at least three times. Experiments were performed on Kelly cells transfected with an empty vector, wild-type or the mutated ribonuclease domain-deprived MCPIP1, BE(2)-C cells transfected with negative control or miRNA-3613-3p mimic and LAN-1 cells transfected with negative control or miRNA-3613-3p inhibitor. Pairwise t-tests were performed to compare the differences between the means of the NC vs. 3613-3p. For comparison of more than two means, one-way analysis of variance with Tukey's post hoc test implemented in Statistica (version 13; StatSoft, Inc., Tulsa, OK, USA) was performed. $\mathrm{P}<0.05$ was considered to indicate a statistically significant difference.

\section{Results}

miRNA-3613-3p is differentially expressed in a range of human neuroblastoma cell lines. The expression levels of miRNA-3613-3p were determined in seven human neuroblastoma cell lines and a prostate cancer cell line PC3, which was used as a positive control, as the expression of miRNA-3613-3p in the PC3 cell line has been identified previously (27-29). In total, six of the neuroblastoma cell lines analyzed were characterized by MYCN amplification [Kelly, CHP-134, IMR-32,
LAN-1, LAN-5 and BE(2)-C], whereas SK-N-SH exhibited only two copies of the oncogene. The highest endogenous expression of miRNA-3613-3p was observed in LAN-1 cells, whereby the mean level of miRNA-3613-3p was increased $\sim 6$-fold compared with that in PC3 prostate cancer cells (Fig. 1A). In Kelly, IMR-32 and LAN-5 cell lines, the mean expression level of miRNA-3613-3p was only slightly higher (between 1.5- and 2-fold increased) compared with that in PC3 cells (Fig. 1A). In three human neuroblastoma cell lines, SK-N-SH, CHP-134 and $\mathrm{BE}(2)-\mathrm{C}$ cells, the expression levels of miRNA-3613-3p were decreased compared with that in PC3 cells. The lowest mean expression of miRNA-3613-3p was observed in BE(2)-C cells, with a $60 \%$ decrease compared with PC3 cells.

In our previous study, it was identified that enforced expression of the ribonuclease MCPIP1 caused significant downregulation of miRNA-3616-3p in human neuroblastoma $\mathrm{BE}(2)-\mathrm{C}$ cells (7). To investigate this observation further, the expression of miRNA-3613-3p was determined in another neuroblastoma cell line with high $M Y C N$ amplification, Kelly, with enforced MCPIP1 expression. The mean levels of miRNA-3613-3p were significantly decreased in cells with enforced MCPIP1 expression (50\% decreased), compared with the control cells (Fig. 1B). However, in Kelly cells overexpressing the mutated form of MCPIP1 protein, deprived of ribonucleolytic activity, no significant differences were observed in miRNA-3613-3p expression (Fig. 1B). These results indicated that the precursor form of miRNA-3613-3p may be cleaved directly by the MCPIP1 protein. Visualization of the precursor form of miRNA-3613-3p uncovered a characteristic pyrimidine-purine-pyrimidine loop sequence (CAU) (Fig. 1C) that has been identified in all MCPIP1 target genes (30).

miRNA-3613-3p potentially regulates pathways involved in neuroblastoma pathogenesis. As the differential gene expression across the cell lines suggests a potential involvement of miRNA-3613-3p in neuroblastoma pathogenesis, miRNA-3613-3p was investigated by bioinformatics analysis using the DIANA TOOLS-miRPath algorithm (21) to determine its possible function in this process. KEGG pathway analysis revealed 44 pathways that may be regulated by miRNA-3613-3p (all $\mathrm{P}<0.05)$. Following a thorough review of the literature, 16 biological processes involved in growth, metastasis or chemoresistance of neuroblastoma associated with miRNA-3613-3p were identified (Fig. 2A). The most important and statistically significant signaling pathways were as follows: Hippo signaling pathway, ubiquitin-mediated proteolysis, Wnt signaling pathway, forkhead box $\mathrm{O}$ signaling pathway and transforming growth factor $\beta$ (TGF $\beta$ ) signaling pathway (Fig. 2A). Furthermore, miRNA-3613-3p was predicted to be involved in various cellular processes including proteoglycan turnover in cancer, tumorigenesis-associated transcriptional dysregulation and regulation of cellular signaling in cancer (Fig. 2A).

Additionally, the predicted targets of miRNA-3613-3p identified on the miRWalk2.0 database were investigated using bioinformatics functional analysis using Gene Ontology and PANTHER algorithms. The examination showed a substantial overlap with the aforementioned KEGG pathway analysis. According to the Gene Ontology algorithm, the majority of the putative miRNA-3613-3p target genes regulate 
A

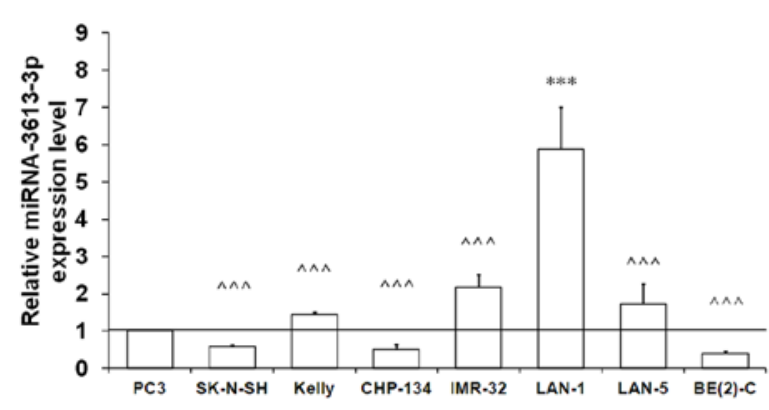

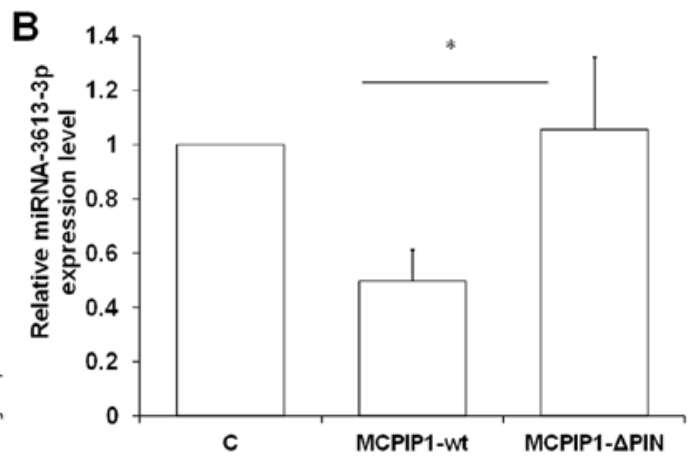

C

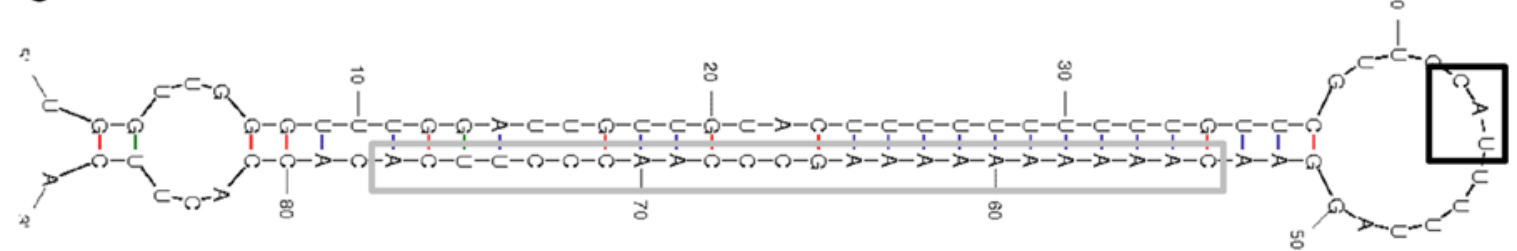

Figure 1. miRNA-3613-3p is differentially expressed in a range of human neuroblastoma cell lines. (A) miRNA-3613-3p expression levels in seven human neuroblastoma cell lines and PC3 prostate cancer cell line determined using RT-qPCR and U6 snRNA as the reference gene. (B) miRNA-3613-3p expression level in Kelly human neuroblastoma cells with enforced expression of the wild-type (MCPIP1-wt) or mutated (MCPIP1- $\Delta$ PIN) form of MCPIP1 protein assessed by RT-qPCR. U6 snRNA was used as the reference gene. Results are presented as the mean \pm standard error of the mean. To compare more than two means, analysis of variance was performed $[(\mathrm{A}) \mathrm{F}(1,7)=15.0046, \mathrm{P}=0.000006$; (B) $\mathrm{F}(1,2)=7.7228$, $\mathrm{P}=0.0291]$. (C) Pre-miRNA-3613-3p secondary structure. The CAU sequence is shown in-frame. ${ }^{*} \mathrm{P}<0.05$ and ${ }^{* * * *} \mathrm{P}<0.001$ vs. control; ${ }^{\wedge \wedge} \mathrm{P}<0.001$ vs. LAN-1. miRNA, microRNA; RT-qPCR, reverse transcription-quantitative polymerase chain reaction; snRNA, small nuclear RNA; MCPIP1, monocyte chemoattractant protein-induced protein 1; C, control; MCPIP1-wt, wild-type MCPIP1; MCPIP1- $\triangle$ PIN, mutated ribonuclease domain-deprived MCPIP1.

tumorigenesis; however, they may also be involved in apoptosis and p53 pathway regulation (Fig. 2B). Bioinformatics functional analysis using PANTHER algorithm revealed a potential involvement of miRNA-3613-3p in the regulation of several signaling pathways important in neuroblastoma pathogenesis, such as the Wnt, TGF $\beta$ or protein kinase B (Akt) signaling pathways (Fig. 2B).

Bioinformatics analysis of predicted miRNA-3613-3p target genes. The identification of mRNAs that interact with a miRNA of interest usually starts by searching multiple databases for predicted miRNA target genes. The algorithms developed for prediction of miRNA-mRNA interactions take into account the miRNA complementarity to the 3'UTR of the transcript. However, certain algorithms additionally use conservation comparison, such as TargetScan or DIANA-microT, whereas others consider binding site accessibility (e.g. PITA and rna22) (31). In our previous study (7), eight putative target genes of miRNA-3613-3p were proposed. In the present study, miRNA-3613-3p was resubjected to thorough bioinformatics analysis using different algorithms and seven of the originally proposed predicted target genes were selected by identifying those that were present in all databases with high probability values, and are involved in neuroblastoma pathogenesis. The genes selected were as follows: $A P A F 1$, DFFB, DICER, NF1, RORA, KIF3A and VHL. Additionally, visualization of miRNA-mRNA duplexes and analysis of the free energy of their binding were performed. Putative binding sites with the free energy of the binding $<-20 \mathrm{kcal} / \mathrm{mol}$ ( $1 \mathrm{kcal}=4.184 \mathrm{~kJ}$ ) were identified for all seven predicted target genes (Fig. 3A and B) (7). Furthermore, the free energies calculated for estimated binding between $D F F B$ or $N F 1$ transcripts and miRNA-3613-3p were $<-25 \mathrm{kcal} / \mathrm{mol}(7)$. The visualization of complementarity between miRNA-3613-3p and the predicted binding sites at the target mRNA 3'UTRs allowed the differentiation of well-defined seed regions at the 5' end of miRNA-3613-3p for all the putative target genes with the exception of DICER. However, the fitting of the DICER transcript and miRNA-3613-3p contained a distinct 3'-supplementary site (Fig. 3A).

Another important factor of miRNA-mediated regulation of gene expression is binding site accessibility, which depends on the secondary structure of a target RNA (31). The difference in the free energy of the base-pairing interactions between miRNA-3613-3p and the mRNAs, and within the mRNA sequence itself, were calculated and are presented as the PITA score (Table I). The general consensus is that predicted targets with PITA scores <-10 kcal/mol are functional (genie.weizmann.ac.il/pubs/mir07/mir07_notes.html). Such differences in free energy of base pairing interactions between miRNAs and mRNAs, and within the target sequence were identified for $D F F B, N F 1$ and RORA (Table I). Although the effect of miRNA-mediated gene silencing depends on the miRNA concentration, even sites with PITA scores $>-10 \mathrm{kcal} / \mathrm{mol}$ may be functional in cells with high expression of a certain miRNA (29). Therefore, it was decided not to exclude any of the predicted target genes from further experimental verification on the basis of the PITA score.

Enforced expression of miRNA-3613-3p causes a significant decrease in the expression of several predicted target genes. Human BE(2)-C neuroblastoma cells were transfected with miRNA-3613-3p mimic to increase the level of miRNA-3613-3p. This cell line was selected for transfection 


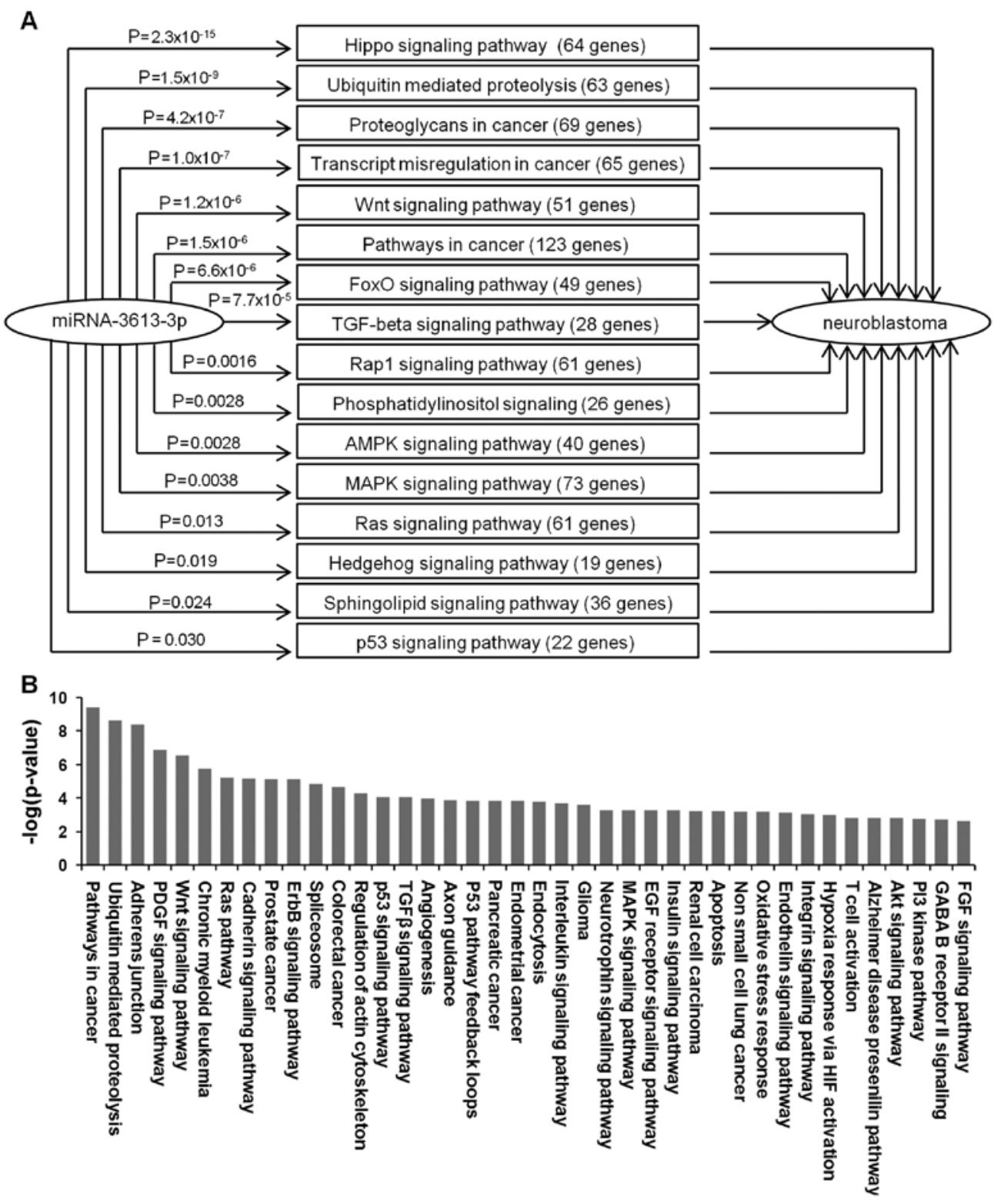

Figure 2. Bioinformatic analysis of the potential involvement of miRNA-3613-3p in neuroblastoma pathogenesis. (A) Potential Kyoto Encyclopedia of Genes and Genomes miRNA-3613-3p target pathways identified through literature research with involvement in neuroblastoma growth, metastasis or chemoresistance. (B) Bioinformatic functional analysis of the processes regulated by predicted miRNA-3613-3p target genes generated using Gene Ontology and the PANTHER algorithm. miRNA, microRNA; FoxO, forkhead box O; TGF, transforming growth factor; AMPK, AMP-activated protein kinase; MAPK, mitogen-activated protein kinase; FGF, fibroblast growth factor; GABA, $\gamma$-aminobutyric acid; PI3 kinase, phosphoinositide 3-kinase; Akt, protein kinase B; EGF, epidermal growth factor; PDGF, platelet-derived growth factor.

with miRNA mimic as it expressed the lowest endogenous level of miRNA-3613-3p (Fig. 1A). As miRNA-mediated gene silencing depends on the concentration of a certain miRNA in the cell (32), three different concentrations of the miRNA mimic were used for transfection (30, 40 and $50 \mathrm{nM})$. The mean level of enforced expression in $\mathrm{BE}(2)$-C cells transfected with the $40 \mathrm{nM}$ concentration of the mimic was increased $\sim 6$-fold compared with that in the cells transfected with miRNA mimic at the $30 \mathrm{nM}$ concentration (Fig. 3C). Of note, the mean expression level of miRNA-3613-3p in the cells transfected with the highest concentration of the mimic $(50 \mathrm{nM})$ was lower compared with cells transfected with the two other miRNA-3613-3p mimic concentrations (30 and $40 \mathrm{nM}$ ) (Fig. 3C). This phenomenon may have been caused by the toxic effect of high concentrations of mimic in the cells.
Therefore, the results obtained for the cells transfected with $50 \mathrm{nM}$ mimic should be interpreted with caution.

The first approach to verify the aforementioned predicted target genes of miRNA-3613-3p was to assess their expression levels in BE(2)-C cells transfected with miRNA-3613-3p mimic. In cells transfected with the lowest concentration of mimic, a decrease in mRNA levels to $80 \%$ was observed only for APAF1 compared with the control cells transfected with a scrambled oligonucleotide (Fig. 3D). The mean levels of expression of other putative target genes (DICER, DFFB, $V H L, K I F 3 A, R O R A$ and $N F 1$ ) remained unchanged compared with the control cells (Fig. 3D). BE(2)-C cells transfected with $40 \mathrm{nM}$ miRNA mimic were characterized by a significant downregulation in 4/7 predicted target genes, namely $D F F B, A P A F 1, V H L$ and $N F 1$ to between 65 and $75 \%$ of 
A

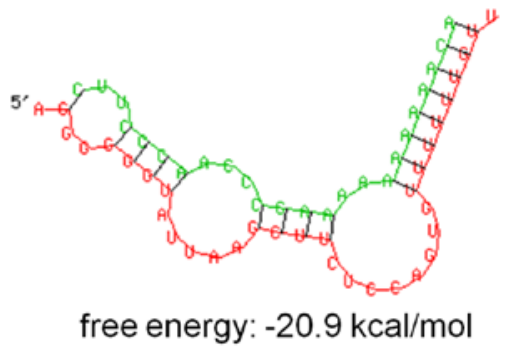

C

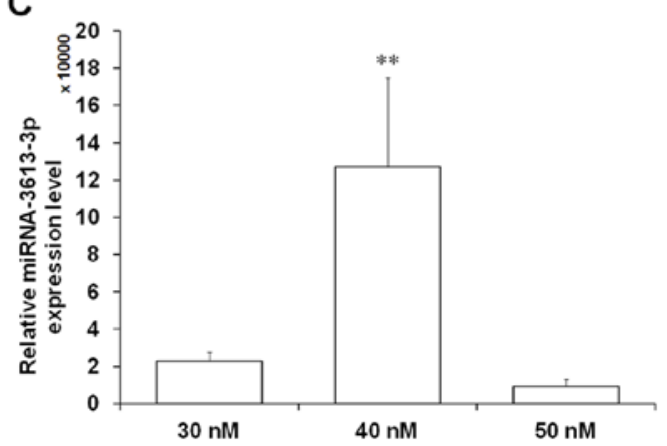

E

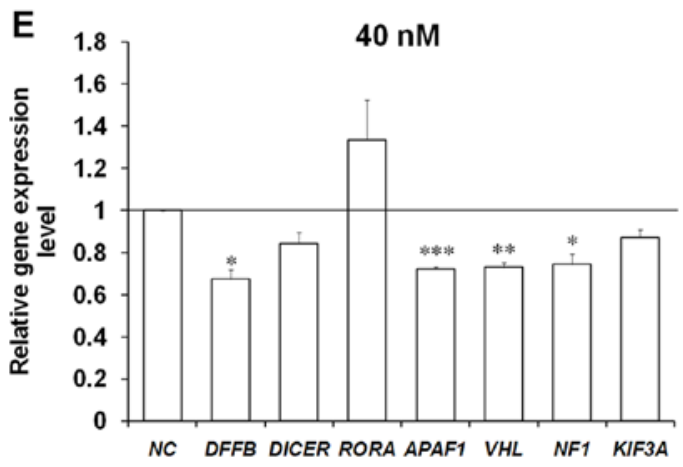

B

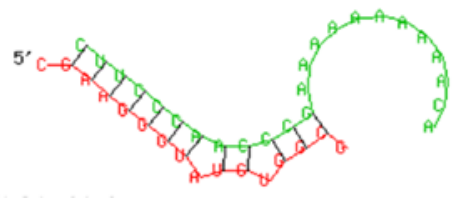

free energy: $-21.8 \mathrm{kcal} / \mathrm{mol}$
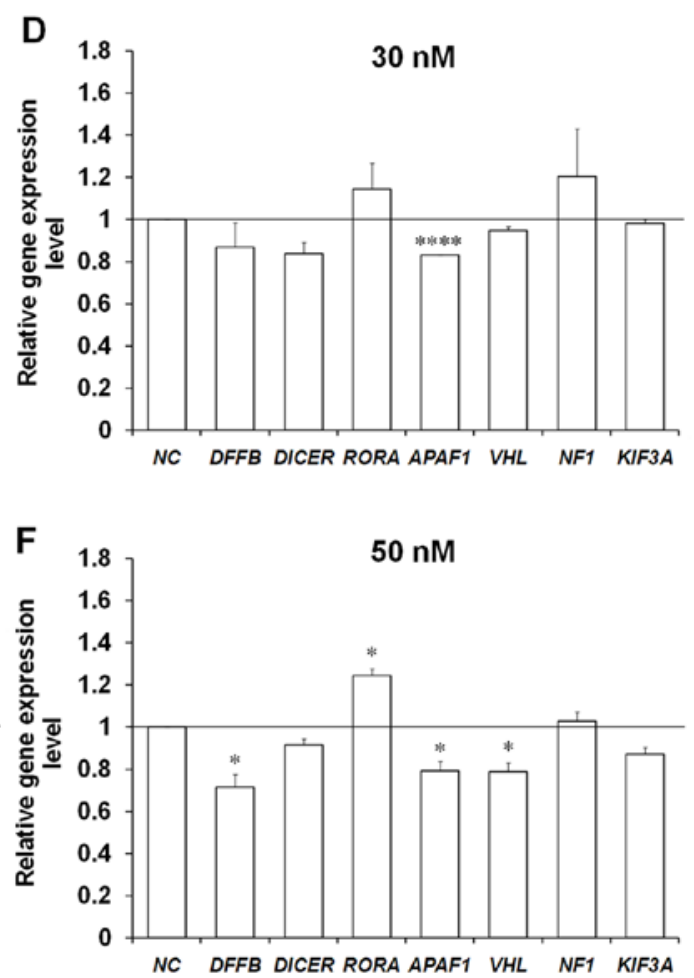

Figure 3. Enforced expression of miRNA-3613-3p causes a significant decrease in the expression of certain of its predicted target genes in the BE(2)-C human neuroblastoma cell line. The visualization of complementarity regions of miRNA-3613-3p and (A) DICER or (B) APAF1 mRNA, and calculation of free energy of the binding. The miRNA sequence is indicated in green and the target mRNA sequence is indicated in red. (C) Expression levels of miRNA-3613-3p in the transfected cells measured using RT-qPCR with U6 small nuclear RNA used as the reference. Expression levels of seven predicted miRNA-3613-3p target genes assessed using RT-qPCR in BE(2)-C cells transfected with miRNA-3613-3p mimic at (D) 30 , (E) 40 and (F) $50 \mathrm{nM}$. $40 \mathrm{~S}$ ribosomal protein S13 was used as the reference gene. Results are presented as the mean \pm standard error of the mean. To compare more than two means, analysis of variance was performed [(A) $\mathrm{F}(1,3)=9.36334, \mathrm{P}=0.01111]$. ${ }^{*} \mathrm{P}<0.05,{ }^{* *} \mathrm{P}<0.01,{ }^{* * *} \mathrm{P}<0.001$ and ${ }^{* * * * *} \mathrm{P}<0.0001$ vs. NC. miRNA, microRNA; RT-qPCR, reverse transcription-quantitative polymerase chain reaction; NC, negative control (scrambled oligonucleotide); $D F F B$, DNA fragmentation factor subunit $\beta$; RORA, retinoic acid-related orphan receptor $\alpha$; APAF1, apoptotic protease-activating factor 1; VHL, von Hippel-Lindau protein; NF1, neurofibromin 1; KIF3A, kinesin family member 3A.

control levels (Fig. 3E). As the mean overexpression of the miRNA in cells transfected with $40 \mathrm{nM}$ mimic was increased 6-fold compared with cells transfected with the $30 \mathrm{nM}$ group (Fig. 3C), it was hypothesized that an increased level of enforced miRNA-3613-3p expression leads to more potent silencing of the putative target genes. Although the level of miRNA-3613-3p in the cells transfected with $50 \mathrm{nM}$ miRNA mimic was decreased compared with the cells transfected with $30 \mathrm{nM}$ miRNA mimic (Fig. 3C), a significant decrease in the mean expression levels of $D F F B, A P A F 1$ and $V H L$, to $80 \%$ of the control, was observed (Fig. $3 \mathrm{~F}$ ).

To examine further the possible regulatory mechanisms by miRNA-3613-3p on the predicted target genes, the relative protein levels of two of the aforementioned seven putative targets were determined. APAFl was selected as its gene expression was significantly decreased in the cells transfected with miRNA mimic at all concentrations (Fig. 3D-F).
Furthermore, the relative protein levels of DICER in the transfected cells were determined, as it has a crucial function in miRNA biogenesis (33). Examination of the possible binding between miRNA-3613-3p and APAF1 or DICER mRNAs uncovered putative binding sites with low free energies in the base pairing of the two transcripts (Fig. 3A and B). No significant alterations were identified in the protein levels of APAF1 and DICER in cells transfected with the mimic at $30 \mathrm{nM}$ compared with in the control cells (Fig. 4A). Western blot analysis of APAF1 levels in the cells transfected with $40 \mathrm{nM}$ miRNA-3613-3p mimic revealed that its signal was downregulated to between 70 and $80 \%$ of that of the control (Fig. 4B). Similarly, DICER protein expression was downregulated only in cells transfected with $40 \mathrm{nM}$ mimic (Fig. 4B). These results confirmed that a higher concentration of miRNA-3613-3p in $\mathrm{BE}(2)-\mathrm{C}$ neuroblastoma cells provided more potent silencing of the predicted target genes at the protein level. 

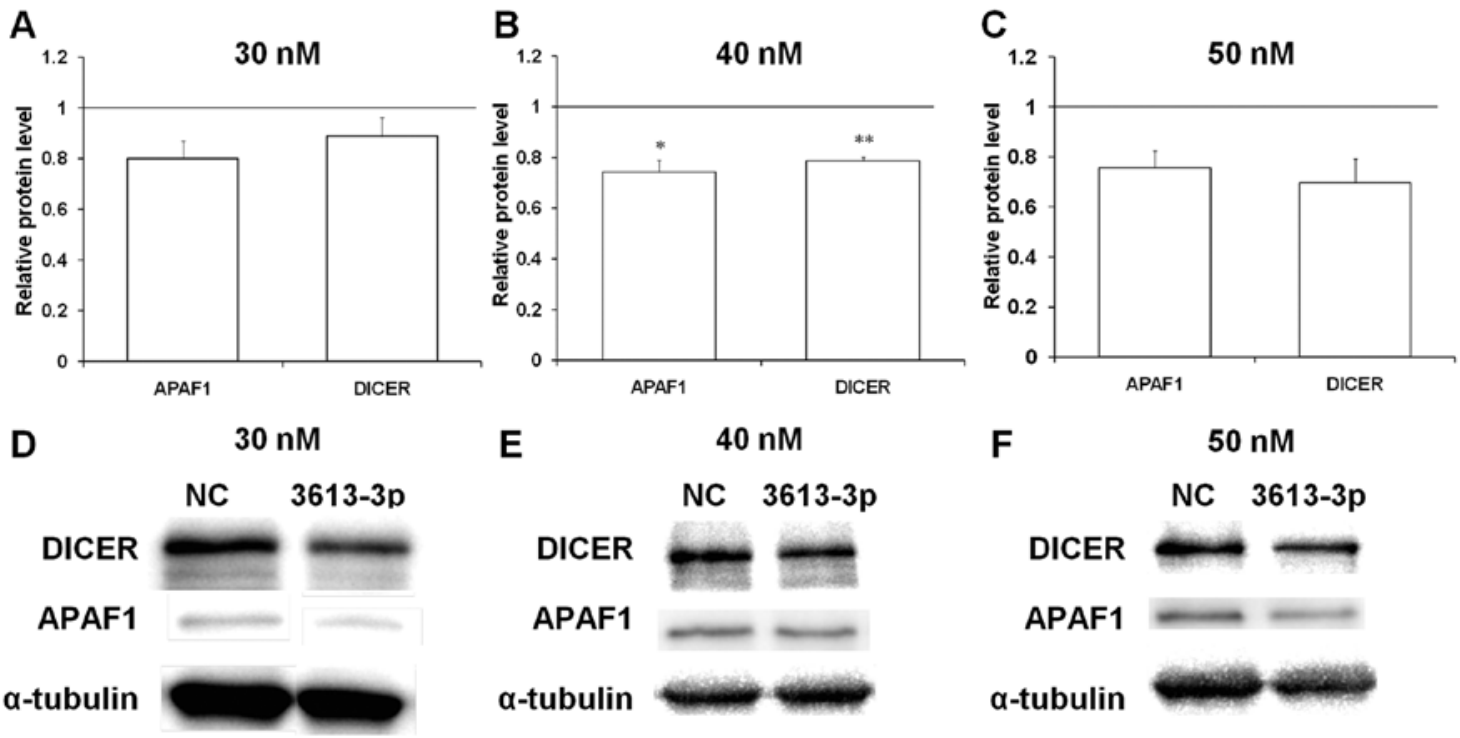

Figure 4. Enforced expression of miRNA-3613-3p causes a significant decrease in APAF1 and DICER protein levels in human neuroblastoma BE(2)-C cells Relative APAF1 and DICER levels in BE(2)-C cells transfected with miRNA-3613-3p mimic at (A) 30, (B) 40 and (C) $50 \mathrm{nM}$ were determined by western blotting. $\alpha$-tubulin was used as the reference protein. Results are presented as the mean \pm standard error of the mean. Representative images of DICER, APAF1 and the $\alpha$-tubulin levels in cells transfected with miRNA-3613-3p mimic at (D) 30, (E) $40 \mathrm{nM}$ and (F) $50 \mathrm{nM}$. ${ }^{*} \mathrm{P}<0.05$ and ${ }^{* * *} \mathrm{P}<0.01 \mathrm{vs.} \mathrm{NC}$. miRNA, microRNA; APAF1, apoptotic protease-activating factor 1 ; NC, negative control.
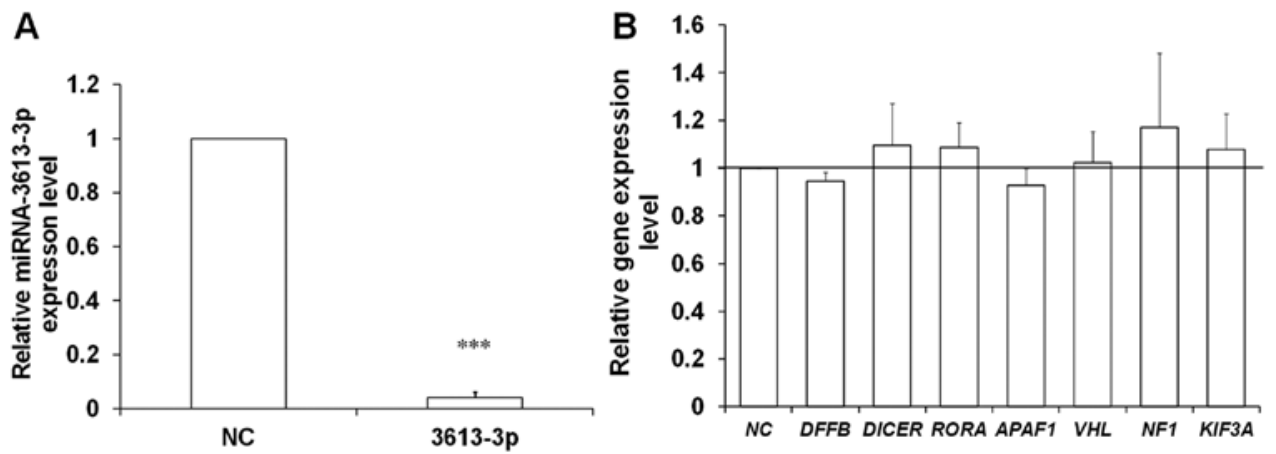

Figure 5. Downregulation of miRNA-3613-3p does not affect expression of predicted target genes of the miRNA investigated. (A) Relative miRNA-3613-3p expression levels in LAN-1 cells transfected with miRNA-3613-3p inhibitor determined using RT-qPCR with U6 small nuclear RNA used as the reference. (B) Expression levels of the predicted target genes of the miRNA investigated in LAN-1 cells transfected with miRNA-3613-3p inhibitor determined using RT-qPCR with 40S ribosomal protein S13 used as a reference gene (B). All experiments were performed three times in triplicate. Results are presented as the mean \pm standard error of the mean. ${ }^{* * *} \mathrm{P}<0.001$ vs. NC. miRNA, microRNA; RT-qPCR, reverse transcription-polymerase chain reaction; NC, negative control; $D F F B$, DNA fragmentation factor subunit $\beta ; R O R A$, retinoic acid-related orphan receptor $\alpha ; A P A F 1$, apoptotic protease-activating factor 1; $V H L$, von Hippel-Lindau protein; $N F 1$, neurofibromin 1; KIF3A, kinesin family member 3A.

On the basis of the aforementioned results, $A P A F l$ was selected as the most likely target gene of miRNA-3613-3p and subjected to further verification. The expression of this gene was decreased upon enforced expression of miRNA-3613-3p in all tested conditions at the mRNA and protein levels (Figs. 3D-F and 4).

Downregulation of miRNA-3613-3p in LAN-1 neuroblastoma cells does not affect the expression of putative target genes. Additionally, in order to obtain the downregulation of the miRNA investigated, LAN-1 neuroblastoma cells were transfected with miRNA-3613-3p inhibitor. This cell line was selected for the transfection with the inhibitors owing to its having the highest endogenous miRNA-3613-3p expression (Fig. 1A). The level of silencing achieved of the miRNA investigated was significantly potent, at $\sim 7 \%$ of the control (Fig. 5A).
To examine further the effect of the altered miRNA-3613-3p levels on the putative target gene expression, the mRNA levels of all seven predicted target transcripts were assessed in LAN-1 cells transfected with the inhibitors. As expected, the expression of $D F F B, A P A F 1, V H L$ and $N F 1$ genes was not decreased in this model. In addition, an increase in the expression of the putative miRNA-3613-3p target genes was not observed (Fig. 5B). However, the endogenous level of miRNA-3613-3p in LAN-1 neuroblastoma cells was four orders of magnitude lower compared with in BE(2)-C cells transfected with the mimic. Furthermore, the decrease in the predicted target genes in the $\mathrm{BE}(2)-\mathrm{C}$ cells upon upregulation of the miRNA investigated was $\sim 30 \%$ compared with the control (Fig. 3D-F). Therefore, the lack of enhanced putative miRNA-3613-3p target gene expression in LAN-1 cells transfected with the inhibitors was not unforeseen. 
A

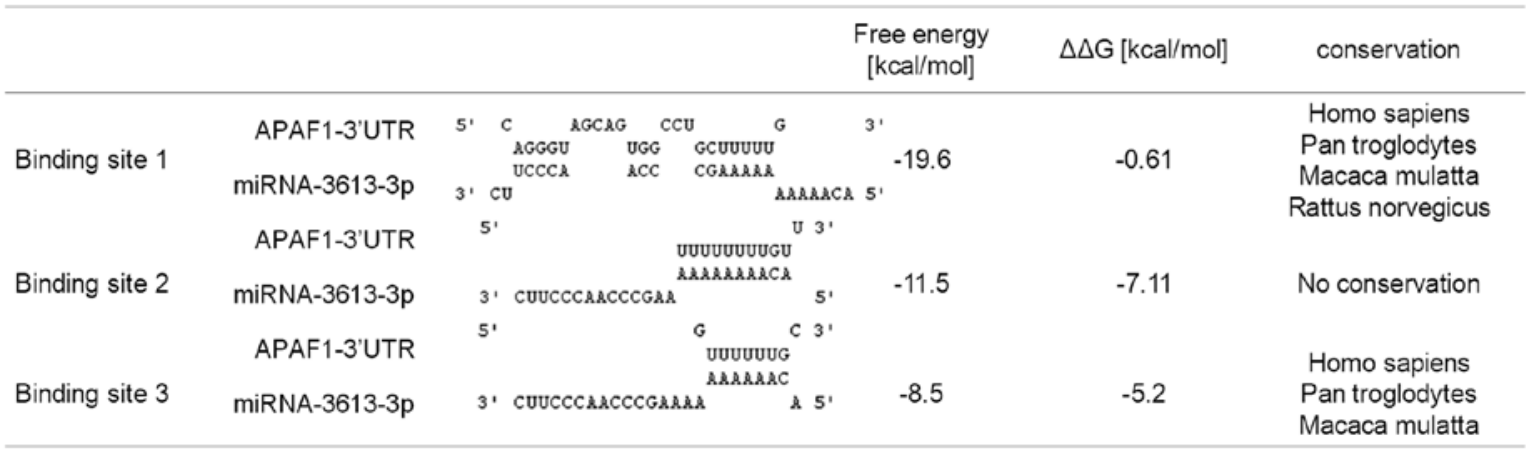

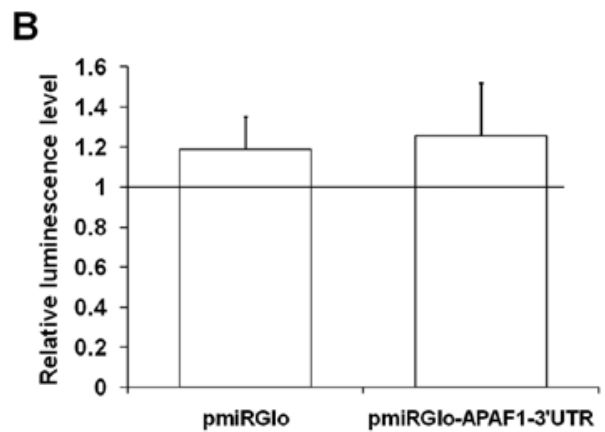

Figure 6. miRNA-3613-3p does not directly target predicted binding sites in the APAF1 3'UTR of BE(2)-C cells. (A) Putative binding sites for miRNA-3613-3p in the APAF1 3'UTR. (B) Relative luciferase activity was determined in BE(2)-C cells co-transfected with miRNA-3613-3p mimic or NC, and pmiRGlo or pmiRGlo-APAF1-3'UTR. Results are presented as the mean \pm standard error of the mean. miRNA, microRNA; APAF1, apoptotic protease-activating factor 1; UTR, untranslated region; NC, negative control.

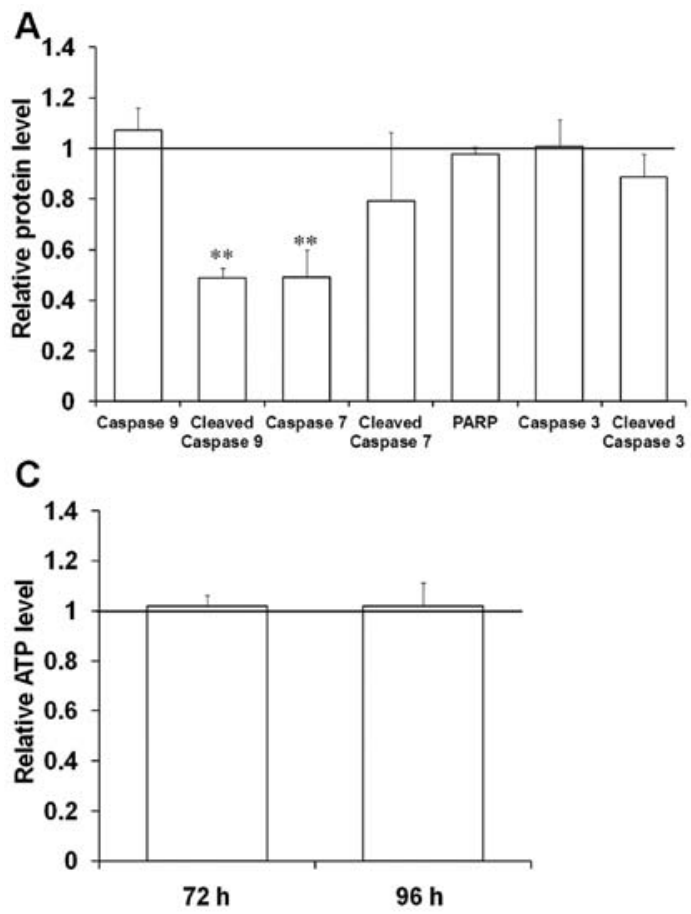

B

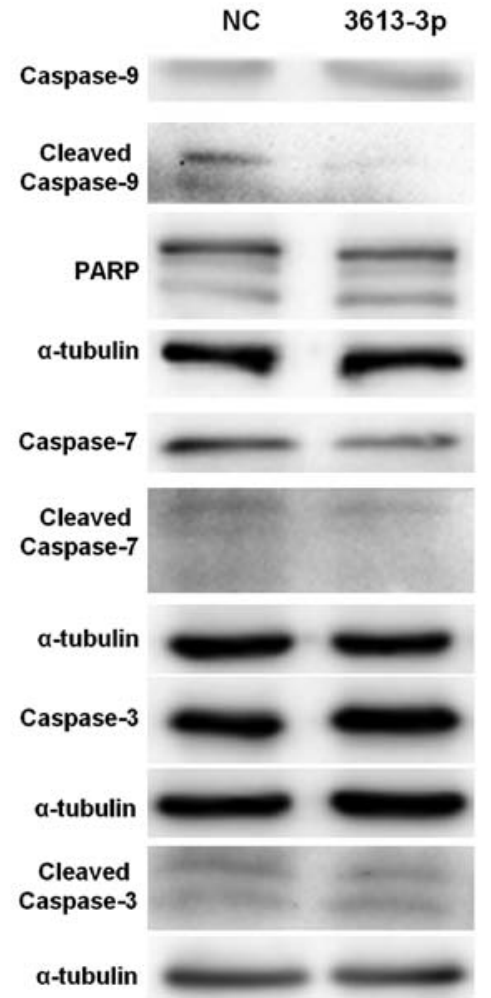

Figure 7. Enforced expression of miRNA-3613-3p causes a decrease in the expression or activation of selected proteins involved in apoptosis in the BE(2)-C human neuroblastoma cell line. (A) Relative levels of selected proteins involved in the apoptosis pathway were determined in BE(2)-C human neuroblastoma cells with miRNA-3613-3p overexpression after $96 \mathrm{~h}$ using western blot analysis. $\alpha$-tubulin was used as the reference protein. (B) Representative images of caspase-9, cleaved caspase-9, caspase-7, cleaved caspase-7, PARP, caspase-3, cleaved caspase-3 and $\alpha$-tubulin levels in BE(2)-C cells with miRNA-3613-3p overexpression after $96 \mathrm{~h}$. (C) Relative ATP level in BE(2)-C cells with ectopic expression of miRNA-3613-3p after 72 and $96 \mathrm{~h}$. Results are presented as the mean \pm standard error of the mean. ${ }^{* *} \mathrm{P}<0.01$ vs. NC. miRNA, microRNA; PARP, poly(ADP-ribose) polymerase; NC negative control. 
Putative binding sites for miRNA-3613-3p predicted in the APAF1 sequence are not functional. Three putative binding sites for miRNA-3613-3p were predicted in the APAF1 3'UTR (Fig. 6A). The free energies of the binding between miRNA-3613-3p and APAF1 mRNA varied between -8.5 and $-20 \mathrm{kcal} / \mathrm{mol}$ (Fig. 6A). Additionally, the differences between the free energies of the base-pairing interactions between miRNA-3613-3p and APAF1 mRNA, and within the mRNA, were calculated using the PITA algorithm. The analysis revealed lower free energies of the miRNA-mRNA binding compared with base-pairing interactions within the mRNA sequence, although for binding site 1 , the difference was minimal (Fig. 6A). Taking into account the fact that cross-species conservation is usually observed for functional miRNA-binding sites (31), the conservation of the three predicted binding sites was investigated. Bioinformatics analysis revealed that predicted binding sites 1 and 3, but not 2, are conserved across species (Fig. 6A).

For experimental verification of the interaction between the putative binding sites in the APAF1 3'UTR sequence and miRNA-3613-3p, luciferase reporter assays were performed. It was identified that miRNA-3613-3p did not affect the luciferase activity in cells transfected with the pmiRGlo vector containing the predicted binding sites of miRNA-3613-3p cloned from the APAF1 3'UTR (Fig. 6B). This result provides evidence for the lack of specific binding of miRNA-3613-3p to the predicted binding sites in the APAF1 3'UTR. Therefore, the observed downregulation of $A P A F 1$ expression following miRNA-3613-3p overexpression (Figs. 3D-F and 4) may not have been caused by the direct interactions between the $A P A F 1$ and miRNA-3613-3p sequences.

Enforced expression of miRNA-3613-3p affects the levels and activation of selected proteins involved in apoptosis in the BE(2)-C human neuroblastoma cell line. As the APAF1 protein serves a crucial function in the triggering of caspase cascades via the intracellular apoptotic pathway (34), the levels and activation of the important proteins involved in this process was investigated in cells with miRNA-3613-3p overexpression. The western blot analysis results revealed that the protein expression of PARP, caspase-3, cleaved caspase-3 and caspase- 9 remained unchanged in cells transfected with miRNA mimic (Fig. 7A and B). However, the relative protein levels of caspase-7 significantly decreased to $50 \%$ of the control group upon miRNA-3613-3p overexpression (Fig. 7A and B). APAF1 protein facilitates proteolytic cleavage and activation of caspase-9 following the release of cytochrome $c$ from mitochondria (34). As the cells transfected with miRNA-3613-3p mimic were characterized by a decrease in APAFl expression levels, it was expected that the activation of the caspase- 9 protein would be affected. A significant downregulation in cleaved caspase- 9 expression in the cells with miRNA-3613-3p overexpression to $50 \%$ of the control was observed (Fig. 7A and B). Furthermore, the level of inactive caspase-9 remained unchanged in cells with miRNA-3613-3p overexpression (Fig. 7A and B). Thus, miRNA-3613-3p may have disrupted caspase-9 activation via APAF1 downregulation.

Apoptosis activation in cells serves a crucial function in the regulation of cellular growth and survival. Measurement
Table I. Bioinformatics analysis of putative binding sites of target mRNAs.

\begin{tabular}{lcc}
\hline Gene & No. of sites & PITA score \\
\hline$A P A F 1$ & 55 & -7.4 \\
$D F F B$ & 53 & -11.53 \\
DICER & 151 & -7.78 \\
NF1 & 247 & -14.9 \\
RORA & 225 & -11.88 \\
KIF3A & 127 & -9.37 \\
VHL & 56 & -9.16 \\
\hline
\end{tabular}

The number of sites is the count of putative binding sites with a seed size $\geq 8$ nucleotides long. The PITA score represents the overall effect of all binding sites combined together on the given UTR. The score is a $\Delta \Delta G$ value in $\mathrm{kcal} / \mathrm{mol}$ between the base-pairing interactions within the mRNA and within the miRNA-mRNA duplex. APAF1, apoptotic protease-activating factor $1 ; D F F B$, DNA fragmentation factor subunit $\beta ; N F 1$, neurofibromin $1 ; R O R A$, retinoic acid-related orphan receptor $\alpha$; KIF3A, kinesin family member $3 \mathrm{~A}$; VHL, von Hippel-Lindau protein; miRNA, microRNA.

of cellular ATP levels is a sensitive and precise method for the assessment of cell viability (35). Therefore, the ATP content in the cells transfected with miRNA-3613-3p mimic was determined to investigate whether miRNA-3613-3p overexpression affects the viability of $\mathrm{BE}(2)-\mathrm{C}$ cells. The transfection of $40 \mathrm{nM}$ miRNA-3613-3p mimic did not significantly change the ATP level in cells after 72 and $96 \mathrm{~h}$ (Fig. 7C). This result indicates that miRNA-3613-3p overexpression does not affect the viability and growth of $\mathrm{BE}(2)-\mathrm{C}$ cells.

\section{Discussion}

Patients with low- and intermediate-risk neuroblastoma may be successfully treated with surgical resection and neo-adjuvant chemotherapy. However, the treatment of high-risk neuroblastoma cases requires aggressive multimodal therapies, including chemotherapy, abscission of the tumor, radiotherapy, 13-cis-retinoic acid-induced cellular differentiation and immunotherapy with anti-GD2 ganglioside antibodies (1). Despite the application of the aforementioned treatment strategies, the event-free survival rate of patients with high-risk neuroblastoma remains $50 \%$ (3). Thus, there is a requirement for the development of novel therapeutic strategies.

miRNA molecules are considered a potential source of novel clinical tools in neuroblastoma $(36,37)$. Differential miRNA expression in distinct subtypes of neuroblastoma as well as the development of miRNA microarrays has enabled the use of miRNA expression patterns as specific biomarkers for disease risk stratification (36). Furthermore, miRNA molecules are present in bodily fluids, including plasma, serum and saliva. Assessment of circulating miRNA expression patterns revealed significant differences between healthy individuals and patients with neuroblastoma (37). The lack of invasiveness of the mode of collection of circulating miRNA samples makes them a likely novel class of precise biomarkers (37). In addition, a number of individual miRNAs have been identified to function 
as potent oncogenes or tumor suppressors, which provides opportunities for the development of miRNA-based therapies (5). One of the strategies is to restore the normal levels of tumor-suppressive miRNA using miRNA mimics, chemically modified oligonucleotides that have the sequence of the naturally occurring miRNA molecule (37). Targeted delivery of miRNA-34a mimic to neuroblastoma cells was demonstrated to inhibit tumor growth in vivo (38). Another potential strategy for miRNA-based therapies is silencing of specific oncogenic miRNA via antagomirs, chemically modified oligonucleotides that have complementary sequences to an endogenous miRNA (39). Injection of miRNA-17-5p antagomirs leads to complete neuroblastoma tumor regression in vivo in $30 \%$ of cases (40). With the increasing possibility of the clinical application of miRNAs in neuroblastoma treatment, it is important to understand the involvement of miRNA-dependent gene regulation networks in disease pathogenesis.

In our previous study, it was demonstrated that MCPIP1 ribonuclease overexpression significantly inhibits the growth and proliferation rate of $\mathrm{BE}(2)-\mathrm{C}$ human neuroblastoma cells (41). Application of miRNA microarrays allowed for the delineation of miRNA expression patterns in $\mathrm{BE}(2)-\mathrm{C}$ cells following MCPIP1 overexpression. Of note, the most significantly downregulated miRNA upon MCPIP1 overexpression was a novel miRNA, miRNA-3613-3p (7), which, to the best of our knowledge, had not been previously investigated in neuroblastoma. Deregulation of miRNA-3613-3p expression in Kelly and BE(2)-C cells with MCPIP1 overexpression, characterized by inhibition of pro-proliferative pathways, suggests its involvement in the regulation of neuroblastoma cell biology. Additionally, it was identified that the overexpression of MCPIP1 protein causes the downregulation of the most potent oncogene in neuroblastoma, $M Y C N$, in two highly tumorigenic cell lines, $\mathrm{BE}(2)-\mathrm{C}$ and Kelly, as well as inhibition of the Akt/mammalian target of rapamycin signaling pathway (17). Of note, the PANTHER algorithm revealed the potential involvement of miRNA-3613-3p in the regulation of the Akt signaling pathway. Further evidence of the involvement of miRNA-3613-3p in neuroblastoma cell biology is the differential expression of miRNA-3613-3p demonstrated in our study in a variety of human neuroblastoma cell lines. Of note, the cell lines characterized by increased miRNA-3613-3p expression (LAN-1, LAN-5, IMR-32 and Kelly), compared with the PC3 cell line, are N-type neuroblastoma cells (42). They adhere poorly to the cell culture plate and exhibit a tendency to aggregate. Furthermore, the cell lines with the lowest endogenous expression of miRNA-3613-3p [BE(2)-C and CHP-134] are I-type neuroblastoma cells, identified by marked adhesion to the cell culture plate and extensive migration $(43,44)$. Thus, there may be an association between the expression level of miRNA-3613-3p and neuroblastoma cell phenotype. Comparison of the expression of the miRNA investigated in neuroblastoma cell lines and the normal cells of the same origin would be worthwhile and may shed more light on the possible oncogenic function of miRNA-3613-3p in the pathogenesis of this type of cancer. Neuroblastoma is an embryonal tumor that arises from the sympathoadrenal cells in the neural crest of the embryo. Owing to technical difficulties and ethical considerations, human embryonic neural crest cells are not available for research purposes. Deriving neural crest cells from human induced pluripotent stem cells appears to be a promising alternative and is currently being developed by several research groups (45).

An extensive search of the databases and analysis using various bioinformatics software allowed us to select seven putative target genes of miRNA-3613-3p. Of note, all the predicted target genes that were downregulated in cells with miRNA-3613-3p overexpression ( $A P A F 1, D F F B$, $D I C E R, V H L$ and NFI) exhibit a tumor-suppressor potential. $A P A F 1$ encodes a protein crucial for the activation of the caspase cascade in the programmed cell death intracellular pathway (34). $D F F B$, another potential miRNA-3613-3p target gene, encodes a nuclease involved in DNA fragmentation during apoptosis (46). As one of the hallmarks of cancer is resistance to programmed cell death, pro-apoptotic proteins exhibit tumor-suppressive potential in numerous types of cancer (47). Additionally, APAF1 was identified to be a suppressor of another type of tumor of neuroectodermal origin: Melanoma (48). Furthermore, DICER, a putative target gene of miRNA-3613-3p, encodes a key ribonuclease involved in miRNA biogenesis, which supports the finding of global miRNA downregulation in the pathogenesis of neuroblastoma (5). Furthermore, a low expression of this gene was identified to be a prognostic factor for stage 4 neuroblastoma (33). VHL serves a function in neuronal cell differentiation (49). In addition, the expression level of this gene could serve as a biomarker in neuroblastoma, and its downregulation points to a high-risk subtype of the disease (50). NF1 encodes a negative regulator of the mitogen-activated protein kinase signaling pathway and is an important prognostic factor of retinoic acid therapy outcome (51). Additionally, BE(2)-C cells with MCPIP1 protein overexpression and miRNA-3613-3p downregulation are characterized by significant increases in $A P A F 1$ and $D F F B$ levels at the transcriptional and translational levels (7). These results support the data from the present study that demonstrated the downregulation of the expression of the aforementioned genes in $\mathrm{BE}(2)-\mathrm{C}$ cells transfected with miRNA-3613-3p mimic, and may indicate an oncogenic function of miRNA-3613-3p. However, owing to high heterogeneity of neuroblastoma cell lines, it may be difficult to draw general conclusions concerning the function of the gene in the pathogenesis of this type of cancer. Silencing of the miRNA investigated in another neuroblastoma cell line, LAN-1, did not lead to an increase in expression of any of the seven predicted target genes. This may suggest that the action of miRNA-3613-3p depends strongly on the cellular context.

Of the seven putative target genes of miRNA-3613-3p, the downregulation of $A P A F 1$ in cells with miRNA-3613-3p overexpression was the most significant compared with control cells. Despite the presence of the three putative binding sites for miRNA-3613-3p at the 3'UTR of APAF1 mRNA, the reporter gene assay did not signal an interaction between the predicted sequences in the transcript and miRNA-3613-3p. Nevertheless, the APAFl gene may be regulated by miRNA-3613-3p through binding sites at the 5'UTR or coding sequence in the transcript. Alternatively, the downregulation of the gene in cells with miRNA-3613-3p overexpression may be the result of miRNA-3613-3p targeting an activator of $A P A F 1$, subsequently downregulating $A P A F 1$ expression indirectly. 
The protein product of the $A P A F 1$ gene serves a key function in the activation of the caspase cascade in the intracellular apoptotic pathway. Following release from the mitochondria, cytochrome $c$ forms a complex with the APAF1 oligomer. This interaction allows caspase- 9 to be cleaved and activated, which consequently leads to the proteolytic activation of executive caspases, such as caspases-7 and -3 , resulting in apoptosis (34). Analysis of the expression and activation of several proteins involved in programmed cell death in cells transfected with the miRNA-3613-3p mimic produced notable results. A significant decrease was observed in the level of activated cleaved caspase-9 in human BE(2)-C neuroblastoma cells. This is in accordance with the aforementioned decrease in the expression of the activator of this caspase, APAF1 protein, in cells transfected with the miRNA-3613-3p mimic. Inhibition of caspase-9 proteolysis in cells with ectopic miRNA-3613-3p expression may limit the possibility of activating the apoptosis process. Furthermore, in cells with miRNA-3613-3p overexpression, no alterations in the levels and activation of the executive caspase-3 and PARP protein, responsible for DNA fragmentation during the last phase of the apoptosis process (52), were identified. This confirms further a lack of activation of the programmed cell death process following miRNA-3613-3p overexpression in human BE(2)-C neuroblastoma cells.

In conclusion, the results of the present study identified that miRNA-3613-3p may directly or indirectly regulate the expression of several genes with tumor suppressor potential (APAF1, DFFB, NF1, VHL and DICER) in human neuroblastoma cells. The most likely target gene of miRNA-3613-3p appears to be $A P A F 1$; however, this interaction might not be direct. Transfection with miRNA mimic did not result in the activation of $\mathrm{BE}(2)-\mathrm{C}$ cell apoptosis after $96 \mathrm{~h}$. However, it may inhibit this process by lowering caspase- 9 proteolysis via downregulation of APAF1 protein. Additionally, it was identified that enforced expression of miRNA-3613-3p does not affect the viability of $\mathrm{BE}(2)-\mathrm{C}$ cells. The results obtained indicate a possible tumor-promoting function of miRNA-3613-3p in $\mathrm{BE}(2)-\mathrm{C}$ neuroblastoma cells.

\section{Acknowledgements}

Not applicable.

\section{Funding}

The present study was supported by a grant from the Research Project Competition for Young Researchers and PhD Students of the Faculty of Biochemistry, Biophysics and Biotechnology Jagiellonian University (grant no. 12/2016) and a grant from the Polish National Science (grant no. 2011/03/B/NZ1/00024). The Faculty of Biochemistry, Biophysics and Biotechnology of Jagiellonian University is a partner of the Leading National Research Center (KNOW) supported by the Ministry of Science and Higher Education.

\section{Availability of data and materials}

Data sharing is not applicable to this article, as no datasets were generated or analyzed during the current study.

\section{Authors' contributions}

IN, EB and MD performed experiments and acquired data; IN interpreted the data; IN designed experiments and drafted the manuscript; HR and IH edited the manuscript. All authors approved the final content for journal submission and publication.

\section{Ethics approval and consent to participate}

Not applicable.

\section{Patient consent for publication}

Not applicable.

\section{Competing interests}

The authors declare that they have no competing interests.

\section{References}

1. Louis CU and Shohet JM: Neuroblastoma: Molecular pathogenesis and therapy. Annu Rev Med 66: 49-63, 2015.

2. Maris JM,Hogarty MD, Bagatell R and Cohn SL: Neuroblastoma. Lancet 369: 2106-2120, 2007.

3. Pinto NR, Applebaum MA, Volchenboum SL, Matthay KK, London WB, Ambros PF, Nakagawara A, Berthold F, Schleiermacher G, Park JR, et al: Advances in risk classification and treatment strategies for neuroblastoma. J Clin Oncol 33: 3008-3017, 2015.

4. de Carvalho IN, de Freitas RM and Vargas FR: Translating microRNAs into biomarkers: What is new for pediatric cancer? Med Oncol 33: 49, 2016

5. Zhi F, Wang R, Wang Q, Xue L, Deng D, Wang S and Yang Y: MicroRNAs in neuroblastoma: Small-sized players with a large impact. Neurochem Res 39: 613-623, 2014.

6. Mei H, Lin ZY and Tong QS: The roles of microRNAs in neuroblastoma. World J Pediatr 10: 10-16, 2014.

7. Boratyn E, Nowak I, Horwacik I, Durbas M, Mistarz A, Kukla M, Kaczówka P, Łastowska M, Jura J and Rokita H: Monocyte chemoattractant protein-induced protein 1 overexpression modulates transcriptome, including microRNA, in human neuroblastoma cells. J Cell Biochem 117: 694-707, 2016.

8. Liu H, Chen G, Liang M, Qin H, Rong J, Yao J, Wu Z: Atrial fibrillation alters the microRNA expression profiles of the left atria of patients with mitral stenosis. BMC Cardiovasc Disord 14: 10, 2014.

9. Ji H, Chen M, Greening DW, He W, Rai A, Zhang W and Simpson RJ: Deep sequencing of RNA from three different extracellular vesicle (EV) subtypes released from the human LIM1863 colon cancer cell line uncovers distinct miRNAenrichment signatures. PLoS One 9: e110314, 2014.

10. Wang N, Bu R, Duan Z, Zhang X, Chen P, Li Z, Wu J, Cai G and Chen $X$ : Profiling and initial validation of urinary microRNAs as biomarkers in IgA nephropathy. PeerJ 3: e990, 2015.

11. Pu Q, Huang Y, Lu Y, Peng Y, Zhang J, Feng G, Wang C, Liu L and Dai Y: Tissue-specific and plasma microRNA profiles could be promising biomarkers of histological classification and TNM stage in non-small cell lung cancer. Thorac Cancer 7: 348-354, 2016.

12. Kumar S, Vijayan M and Reddy PH: MicroRNA-455-3p as a potential peripheral biomarker for Alzheimer's disease. Hum Mol Genet 26: 3808-3822, 2017.

13. Singh A, Rooge S, Varshney A, Vasudevan M, Bhardwaj A, Venugopal S, Trehanpati N, Kumar M, Geffers R, Kumar V, et al: Global micro RNA expression profiling in the liver biopsies of Hepatitis B virus infected patients suggests specific miRNA signatures for viral persistence and hepatocellular injury. Hepatology 67: 1695-1709, 2017.

14. Zhang D, Liu E, Kang J, Yang X and Liu H: MiR-3613-3p affects cell proliferation and cell cycle in hepatocellular carcinoma. Oncotarget 8: 93014-93028, 2017.

15. Zhang Y, Kang R, Liu W, Yang Y, Ding R, Huang Q, Meng J, Xiong $\mathrm{L}$ and Guo Z: Identification and analysis of p53-mediated competing endogenous RNA network in human hepatocellular carcinoma. Int J Biol Sci 13: 1213-1221, 2017. 
16. Mizgalska D, Wegrzyn P, Murzyn K, Kasza A, Koj A, Jura J, Jarzab B and Jura J: Interleukin-1-inducible MCPIP protein has structural and functional properties of RNase and participates in degradation of IL-1beta mRNA. FEBS J 276: 7386-7399, 2009.

17. Boratyn E, Nowak I, Durbas M, Horwacik I, Sawicka A and Rokita H: MCPIP1 exogenous overexpression inhibits pathways regulating MYCN oncoprotein stability in neuroblastoma. J Cel Biochem 118: 1741-1755, 2017.

18. Livak KJ and Schmittgen TD: Analysis of relative gene expression data using real-time quantitative PCR and the $2(-\Delta \Delta \mathrm{C}(\mathrm{T}))$ method Methods 25: 402-408, 2001.

19. Smith PK, Krohn RI, Hermanson GT, Mallia AK, Gartner FH, Provenzano MD, Fujimoto EK, Goeke NM, Olson BJ and Klenk DC: Measurement of protein using bicinchoninic acid. Anal Biochem 150: 76-85, 1985.

20. Horwacik I, Durbas M, Boratyn E, Węgrzyn P and Rokita H: Targeting GD2 ganglioside and aurora A kinase as a dual strategy leading to cell death in cultures of human neuroblastoma cells. Cancer Lett 341: 248-264, 2013.

21. Vlachos IS, Zagganas K, Paraskevopoulou MD, Georgakilas G, Karagkouni D, Vergoulis T, Dalamagas T and Hatzigeorgiou AG DIANA-miRPath v3.0: Deciphering microRNA function with experimental support. Nucleic Acids Res 43: W460-6, 2015.

22. Paraskevopoulou M, Georgakilas G, Kostoulas N, Vlachos I, Vergoulis T, Reczko M,Filippidis C, Dalamagas T, Hatzigeorgiou A DIANA-microT web server v5.0: service integration into miRNA functional analysis workflows. Nucleic Acids Res 41: W169-W173 2013.

23. Dweep H and Gretz N: miRWalk2.0: A comprehensive atlas of microRNA-target interactions. Nat Methods 12: 697, 2015.

24. Rehmsmeier M, Steffen P, Hochsmann M and Giegerich R: Fas and effective prediction of microRNA/target duplexes. RNA 10: $1507-1517,2004$

25. Kertesz M, Iovino N, Unnerstall U, Gaul U and Segal E: The role of site accessibility in microRNA target recognition. Nat Genet 39: 1278-1284, 2007

26. Agarwal V, Bell GW, Nam JW and Bartel DP: Predicting effective microRNA target sites in mammalian mRNAs. eLife 4: e05005, 2015.

27. Hessvik NP, Phuyal S, Brech A, Sandvig K and Llorente A: Profiling of microRNAs in exosomes released from $\mathrm{PC}-3$ prostate cancer cells. Biochim Biophys Acta 1819: 1154-1163, 2012.

28. Chiyomaru T, Yamamura S, Fukuhara S, Hidaka H, Majid S, Saini S, Arora S, Deng G, Shahryari V, Chang I, et al: Genistein up-regulates tumor suppressor microRNA-574-3p in prostate cancer. PLoS One 8: e58929, 2013.

29. Sohn EJ, Won G, Lee J, Lee S and Kim SH: Upregulation of miRNA3195 and miRNA374b mediates the anti-angiogenic properties of melatonin in hypoxic PC-3 prostate cancer cells. J Cancer 6: 19-28, 2015

30. Mino T, Murakawa Y, Fukao A, Vandenbon A, Wessels HH, Ori D, Uehata T, Tartey S, Akira S, Suzuki Y, et al: Regnase-1 and Roquin regulate a common element in inflammatory mRNAs by spatiotemporally distinct mechanisms. Cell 161: 1058-1073, 2015

31. Witkos TM, Koscianska E and Krzyzosiak WJ: Practical aspects of microRNA target prediction. Curr Mol Med 11: 93-109, 2011.

32. Shu J, Xia Z, Li L, Liang ET, Slipek N, Shen D, Foo J, Subramanian S and Steer CJ: Dose-dependent differential mRNA target selection and regulation by let-7a-7f and miR-17-92 cluster microRNAs. RNA Biol 9: 1275-1287, 2012

33. Lin RJ, Lin YC, Chen J, Kuo HH, Chen YY, Diccianni MB London WB, Chang $\mathrm{CH}$ and $\mathrm{Yu} \mathrm{AL}$ : microRNA signature and expression of Dicer and Drosha can predict prognosis and delineate risk groups in neuroblastoma. Cancer Res 70: 7841-7850, 2010.

34. Cecconi F: Apaf1 and the apoptotic machinery. Cell Death Differ 6: 1087-1098, 1999.
35. Riss T, Moravec R, Niles A, Duellman S, Benink H, Worzella T and Minor L: Cell Viability Assays in Assay Guidance Manual. Sittampalam G, et al (eds). Eli Lilly \& Company and the National Center for Advancing Translational Sciences, Bethesta, MD, 2013.

36. Stallings RL: MicroRNA involvement in the pathogenesis of neuroblastoma: Potential for microRNA mediated therapeutics. Curr Pharm Des 15: 456-462, 2009.

37. Shalaby T, Fiaschetti G, Baumgartner M and Grotzer MA Significance and therapeutic value of miRNAs in embryonal neural tumors. Molecules 19: 5821-5862, 2014.

38. Tivnan A, Orr WS, Gubala V, Nooney R, Williams DE, McDonagh C, Prenter S, Harvey H, Domingo-Fernández R, Bray IM, et al: Inhibition of neuroblastoma tumor growth by targeted delivery of microRNA-34a using anti-disialoganglioside GD2 coated nanoparticles. PLoS One 7: e38129, 2012.

39. Verissimo CS, Molenaar JJ, Fitzsimons CP and Vreugdenhil E: Neuroblastoma therapy: What is in the pipeline? Endocr Relat Cancer 18: R213-R231, 2011.

40. Fontana L, Fiori ME, Albini S, Cifaldi L, Giovinazzi S, Forloni M, Boldrini R, Donfrancesco A, Federici V, Giacomini P, et al: Antagomir-17-5p abolishes the growth of therapy-resistant neuroblastoma through p21 and BIM. PLoS One 3: e2236, 2008.

41. Skalniak A, Boratyn E, Tyrkalska SD, Horwacik I, Durbas M, Lastowska M, Jura J and Rokita H: Expression of the monocyte chemotactic protein-1-induced protein 1 decreases human neuroblastoma cell survival. Oncol Rep 31: 2385-2392, 2014.

42. Baumann Kubetzko FB, Di Paolo C, Maag C, Meier R, Schäfer BW, Betts DR, Stahel RA and Himmelmann A: The PAX5 oncogene is expressed in N-type neuroblastoma cells and increases tumorigenicity of a S-type cell line. Carcinogenesis 25: 1839-1846, 2004.

43. Voigt A, Hartmann P and Zintl F: Differentiation, proliferation and adhesion of human neuroblastoma cells after treatment with retinoic acid. Cell Adhes Commun 7: 423-440, 2000.

44. Ross R: Cellular heterogeneity. In: Neuroblastoma. Cheung N and Cohn S (eds). Springer, Berlin, pp55-60, 2005.

45. Liu JA and Cheung M: Neural crest stem cells and their potential therapeutic applications. Dev Biol 419: 199-216, 2016.

46. Judson H, van Roy N, Strain L, Vandesompele J, Van Gele M, Speleman F and Bonthron DT: Structure and mutation analysis of the gene encoding DNA fragmentation factor 40 (caspase-activated nuclease), a candidate neuroblastoma tumour suppressor gene. Hum Genet 106: 406-413, 2000.

47. Hanahan D and Weinberg RA: Hallmarks of cancer: The next generation. Cell 144: 646-674, 2011

48. Campioni M, Santini D, Tonini G, Murace R, Dragonetti E, Spugnini EP and Baldi A: Role of Apaf-1, a key regulator of apoptosis, in melanoma progression and chemoresistance. Exp Dermatol 14: 811-818, 2005.

49. Murata H, Tajima N, Nagashima Y, Yao M, Baba M, Goto M, Kawamoto S, Yamamoto I, Okuda K and Kanno H: Von Hippel-Lindau tumor suppressor protein transforms human neuroblastoma cells into functional neuron-like cells. Cancer Res 62: 7004-7011, 2002.

50. Hoebeeck J, Vandesompele J, Nilsson H, De Preter K, Van Roy N, De Smet E, Yigit N, De Paepe A, Laureys G, Påhlman S, et al: The von Hippel-Lindau tumor suppressor gene expression level has prognostic value in neuroblastoma. Int J Cancer 119: 624-629, 2006.

51. Hölzel M, Huang S, Koster J, Ora I, Lakeman A, Caron H, Nijkamp W, Xie J, Callens T, Asgharzadeh S, et al: NF1 is a tumor suppressor in neuroblastoma that determines retinoic acid response and disease outcome. Cell 142: 218-229, 2010.

52. Savitskaya MA and Onishchenko GE: Mechanisms of apoptosis. biochemistry (Mosc) 80: 1393-1405, 2015 